\title{
A Meta-Analysis on the Impact of Gamification over Students' Motivation
}

\author{
Assem Tanirbergenovna Mamekova ${ }^{1, *}$, Nurgul Korgadjanovna Toxanbayeva ${ }^{2}$, \\ Khapiza Tanirbergenovna Naubaeva ${ }^{1}$, Slushash Sabitovna Ongarbayeva ${ }^{3}$ and \\ Kulmariya Nurtaevna Akhmediyeva ${ }^{1}$
}

\author{
${ }^{1}$ Department of Pedagogy and Psychology, Zhetysu State University named after I. Zhansugurov, \\ Kazakhstan \\ ${ }^{2}$ Department of General and Implied Psychology, al-Farabi Kazakh National University, Kazakhstan \\ ${ }^{3}$ Department of Creative Education, Zhetysu State University named after I. Zhansugurov, Kazakhstan
}

\begin{abstract}
Controversy surrounds the effectiveness of educational gamification on learners' motivation to study. Prior papers attempting to summarize the available empirical evidence on the topic encompass too many additional domains like the academic performance so that the motivational point is discentrated. Hence, the current meta-analysis aimed to synthesize research findings limited to the clearly stated impact of gamification on higher education students' academic motivation. Results from random effects proportion meta-analysis applied to seven relevant studies with a total of 368 students showed a pooled proportion of $29.68 \%$. In other words, game design elements incorporated into the learning activities were significantly motivating for only about one-third of participants. The assumption of homogeneity was violated for certain reasons. As part of the discussion, previous scholars' efforts to identify moderating factors of successful gamification were overviewed, and their practicality was questioned. It is concluded that the issue of whether educational gamification can amplify students' learning motivation remains an area for further research.
\end{abstract}

Keywords: Academic performance, game design elements, higher education, self-determination theory.

\section{INTRODUCTION}

Motivation can be perceived as an intrinsic power that greatly redounds to one's volition to take action towards a goal [1]. More germane to an educational context, motivation refers to students' willingness to learn viewed as a driving force of sustained engagement and a catalyst of self-regulated learning, which in turn brings improved academic performance for the most part $[2,3]$. It has been empirically proved that broadening the circle of channels for the knowledge transfer, including gamifying a course, might facilitate learning, particularly in terms of intrinsic motivation [4], that is person's desire for action based on an inherent interest in the task itself [5].

There is a highly cited cognitive theory addressing students' learning motivation, namely selfdetermination theory, which considers the motivation as contingent on human beings' demands for competing, autonomous action (inclusive of making choices), as well as feeling of belongingness with a community and interacting with others [6]. These fundamental psychological needs can be satisfied through various informal learning approaches, including

*Address correspondence to this author at the Department of Pedagogy and Psychology, Zhetysu State University named after I. Zhansugurov, ul. Zhansugurova 187a, Taldykorgan, 040009, Kazakhstan;

E-mail: assemm@internet.ru educational gamification, which should be implemented in accordance with the principles of competence, autonomy, and relatedness expected to be core motivational drivers [7].

Gamification means the deployment of game components in a non-game environment intended to engage individuals [8]. Gamified learning has been extensively reported to propel students' academic motivation, reduce their learning anxiety, draw them in a task, facilitate interaction, and maintain goal-oriented activity [9]. The success is most likely rooted in the use of ludic activities providing an atmosphere conducive to learning, diverse incentives, shortened feedback cycles, and eased attitude towards failure [8].

A dearth of learners' self-regulation and intrinsic motivation to study is widely faced by educators in today's world $[10,11]$. This imbroglio has been documented to correlate with various destructive behaviors and outcomes in an academic context. For instance, an investigation of longitudinal data revealed that learners' early motivation is associated with adequate levels of educational attainment and need for cognition in adulthood, whereas lower academic intrinsic motivation from elementary through high school relates to the risk of shortages in those variables [12]. 
Nevertheless, virtually all previous attempts to assemble the available empirical evidence on the effectiveness of educational gamification cover (in addition to learning motivation) several other constructs like academic performance, engagement, cognitive load, behavioral learning outcome, and so forth motivational point is discentrated. As such, the metaanalysis carried out by [13] strived to orchestrate research on the effects of gamification on cognitive, motivational, and behavioral learning outcomes. Among 16 individual studies that the authors selected for evaluating motivational learning outcomes, one is a book chapter that deals with vocational students, one does not investigate motivation at all, the samples of three primary studies consist of school students, and four are conference proceedings, lecture notes, and a doctoral dissertation, while the grey literature is beyond the scope of the meta-analysis presented here. Besides, five of the 16 studies report outcomes pertaining to participants' task performance, engagement, attitudes toward lessons, or separate components of human motivation but do not provide unambiguous evidence on how the intervention influenced learning motivation per se.

Furthermore, [14] made an effort to explore how the introduction of gamification in educational settings affects students' learning outcomes, including motivation. Out of 30 primary studies selected for that meta-analysis, six are focused on academic achievement, four involve school students, three lack clarity in reporting results concerning motivation level, one relies on qualitative data, one could not be found in references, and another one compares motivation degree between two experimental groups for some reason. Moreover, eleven of the 30 records are dissertations, conference papers, or proceedings. The research, therefore, cannot be deemed relevant to the topic under discussion. Finally, out of 14 papers integrated by [15], only three describe the academic motivation of higher education students impacted by gamified learning, one of which is Spanish-language.

Hence, the debate over whether gamification can encourage learning motivation is open so far. The current meta-analysis aspires to make a contribution to research on the subject by focusing on motivational learning outcomes claimed in relevant empirical studies. The research question is as follows: are higher education students whose learning was gamified experience higher motivation for studying than their pretest levels or those who engaged in more conventional instruction?

\section{METHODOLOGY}

\section{Literature Search Strategy}

A bibliographic review using terms gamification and motivation was run by title and keywords in ScienceDirect, Google Scholar, and Scopus databases. On top of that, we screened the reference lists from meta-analyses undertaken by [13-15]. The current meta-analysis only incorporated experimental and quasi-experimental studies on higher education students providing a quantitative evaluation of the impact of gamified learning interventions on students' intrinsic motivation. Since, within gamification theory, intrinsic motivation is the heart of self-determination that impacts academic success crucially, energizing learners to participate in academic activities without external pressure or incentives. Recent research discovered a positive association between intrinsic motivation and university students' course grades [16, 7] and between intrinsic motivation and performance in an array of domains [17]. If the type of motivation was not specified, then motivation was accepted as motivation in general (conceived as high autonomy and low control), and the data was extracted for analysis. That is, there must have been categorical data reflecting exactly participants' motivation (like survey scores) obviously indicated by the authors as a statistically significant difference between pretest and post-test results or significant dissimilarity between a control group and an experimental one after treatment. Conclusions relying on incomplete, anecdotal, or equivocal evidence were deemed ineligible, and studies with inexplicit research design such as unreported sample size. Only English full-text papers published in peer-reviewed scientific journals between 2011 and 2021 were accepted. Book chapters, conference proceedings, theses, case reports, and alike were excluded.

\section{Data Extraction}

Following the initial screening and removal of duplicates, about fifty remaining records were further assessed. At last, seven studies with a total of 368 subjects (see Table 1) were consensually recognized by the research team as meeting the inclusion criteria. The papers were subjected to the extraction of the data required for a proportion meta-analysis (i. e., group sizes and whether the outcome of interest was achieved in a statistically significant manner) aimed at obtaining a pooled effectiveness rate for educational gamification. Unfortunately, only [18] indicated how 
Table 1: Study Characteristics

\begin{tabular}{|c|c|c|c|c|}
\hline $\begin{array}{l}\text { First author } \\
\text { (year) }\end{array}$ & $\mathbf{N}$ & Intervention & Duration & $\begin{array}{l}\text { Motivation } \\
\text { increased }\end{array}$ \\
\hline $\begin{array}{c}\text { Frost (2015) } \\
{[20]}\end{array}$ & 80 & $\begin{array}{l}\text { Positive grade growth, leaderboard, storyline, lives, and medals } \\
\text { incorporated into a learning management system. }\end{array}$ & Within 3 months & No \\
\hline $\begin{array}{l}\text { Stansbury } \\
(2017)[21]\end{array}$ & 93 & $\begin{array}{l}\text { Several gamification elements (exposition, role-playing } \\
\text { exercises, choice, and others) were implemented into an } \\
\text { educational context }\end{array}$ & $\begin{array}{l}3 \text { times a week for } 50 \text { min } \\
\text { each semester over one } \\
\text { academic year }\end{array}$ & Yes \\
\hline $\begin{array}{l}\text { van Roy } \\
(2018)[22]\end{array}$ & 40 & $\begin{array}{c}\text { Need-supporting game elements (challenges, unannounced } \\
\text { badges and a group competition) implemented in Google + } \\
\text { Communities used in a university course }\end{array}$ & 15 weeks & No \\
\hline $\begin{array}{l}\text { Zainuddin } \\
\text { (2018) } \\
{[1]}\end{array}$ & 61 & $\begin{array}{l}\text { Game-based elements (e.g., scores, points, badges, and } \\
\text { leaderboards) incorporated into the flipped classroom practice } \\
\text { through an online gamification quiz }\end{array}$ & $\begin{array}{l}8 \text { sessions over a } 12 \text {-week } \\
\text { semester }\end{array}$ & Yes \\
\hline $\begin{array}{l}\text { Garcia-Cabot } \\
(2020)[23]\end{array}$ & 27 & $\begin{array}{l}\text { A gamified social e-learning platform (with store, achievements, } \\
\text { tasks, leaderboards, and points) used by students }\end{array}$ & Within 3 months & No \\
\hline $\begin{array}{l}\text { Ferriz-Valero } \\
(2020)[18]\end{array}$ & 127 & $\begin{array}{l}\text { A gamified educational platform including role-playing and the } \\
\text { achievement of points by students }\end{array}$ & $\begin{array}{l}\text { A five-week programme with } \\
\text { a total of } 30 \mathrm{~h}\end{array}$ & No \\
\hline $\begin{array}{l}\text { Kyewski } \\
(2018)[24]\end{array}$ & 20 & $\begin{array}{c}\text { Badges issued for successful task performance and specific } \\
\text { activities within an e-learning course in a higher education } \\
\text { setting }\end{array}$ & 1 semester & No \\
\hline
\end{tabular}

many participants eventually had a positive result, whereas the rest studies just reported the effect for a group as a whole so that no distinctions could be made and the presence or the lack of the target outcome was assigned to all subjects in an intervention group. Owing to the small number of included studies, any precalculation arcsine-based transformations would not work correctly [19], so proportions were entered unchanged.

\section{Statistical Analysis}

The meta-analytic procedure was executed through MedCalc version 20 statistical software (MedCalc Software bv, Ostend, Belgium) and resulted in a forest plot exposing individual and pooled effect estimates with their $95 \%$ confidence intervals, using DerSimonian-Laird weights for the random-effects model. To check whether the data are combinable (homogenous), 12 score ( $>75 \%$ considered pointing to high heterogeneity) and Q-test (alpha set at 5\%) were computed, and a Galbraith plot was generated by means of Meta-Essentials [25].

\section{Ethical Statement}

Ethics approval was not required for this study.

\section{RESULTS}

Forest plot (Figure 1) emerging from this random effects proportion meta-analysis applied to the described studies yielded a summary proportion of $29.68 \%(0.69,76.87)$, which might be construed as approximately $30 \%$ success rate in enhancing students' motivation for learning in case of integrating gamification into the university curriculum. However, the results are undermined by overt heterogeneity across studies demonstrated by both $\mathrm{Q}$-test $\left(\mathrm{P}_{\mathrm{Q}}=\right.$ $0.000)$ and 12 score $(84.24 \%)$. This is bolstered by the distance between the effect estimates in the forest plot. Identifying the possible sources of heterogeneity was impossible in view of the low number of available records.

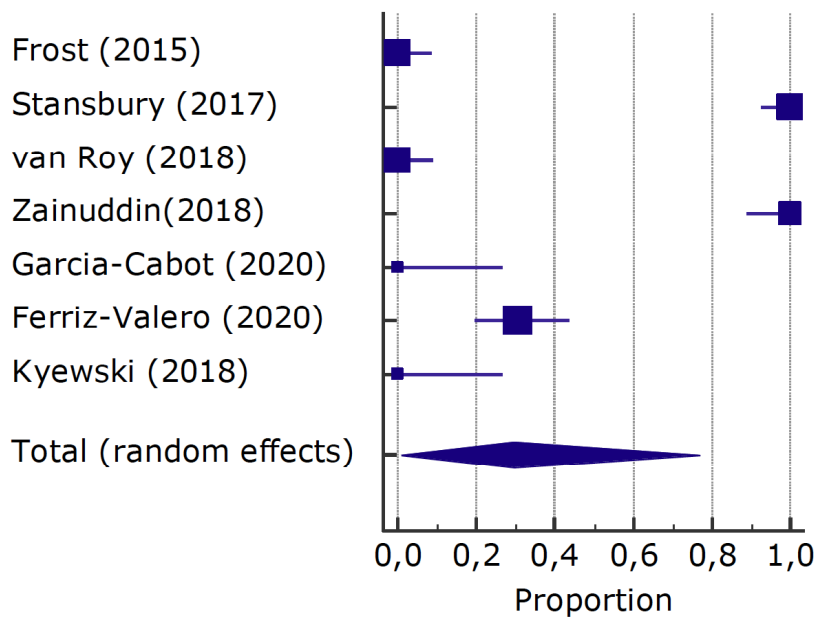

Figure 1: Results of a proportion meta-analysis of studies on the effect of educational gamification on students' motivation. Black squares represent effect estimates (size relative to study weight), whereas the black diamond displays the pooled proportion. Horizontal lines indicate $95 \%$ confidence intervals. 


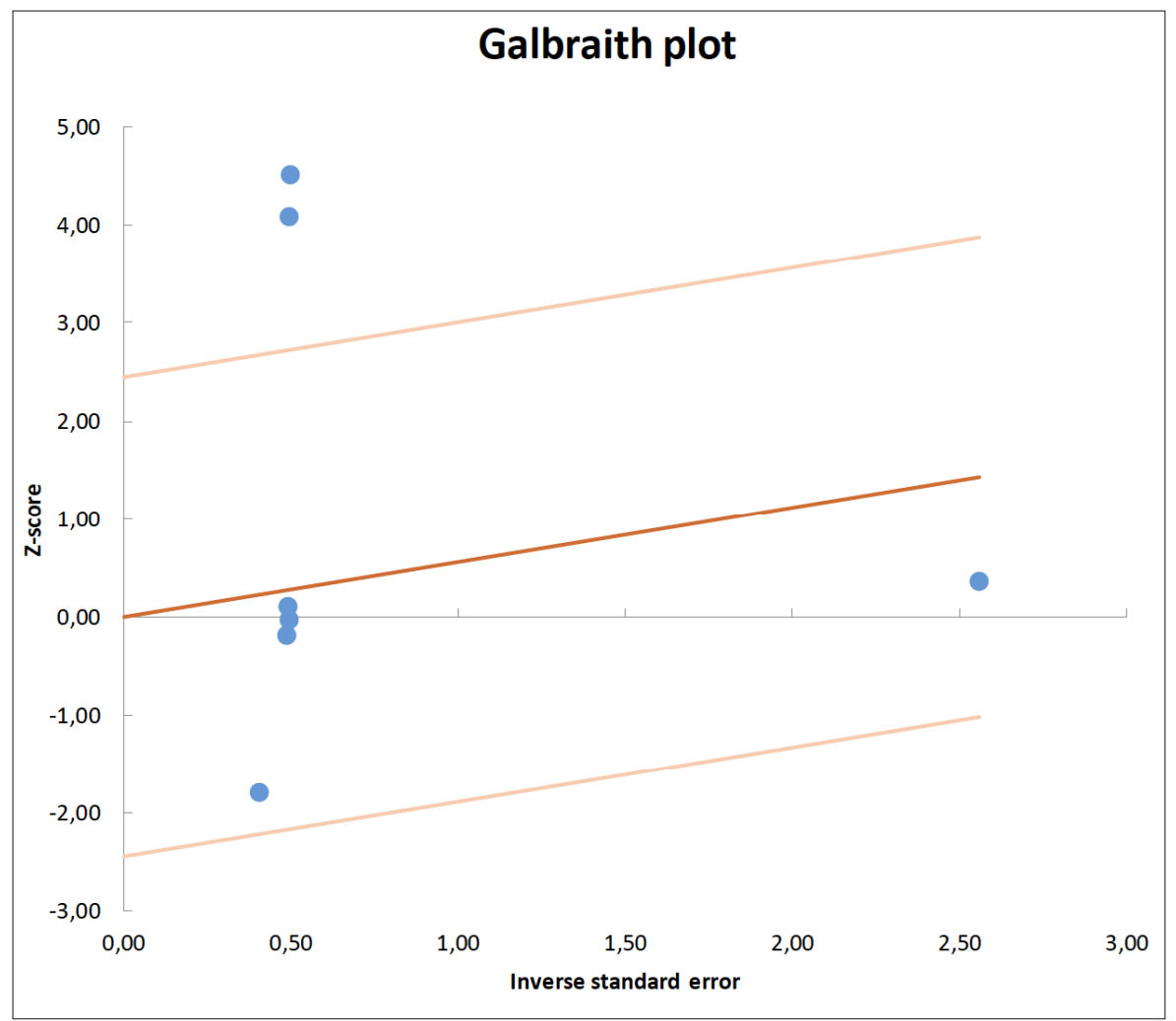

Figure 2: A Galbraith plot for a meta-analysis of studies on the effect of educational gamification on students' motivation. Each dot represents an individual study. Significant heterogeneity and publication bias can be evinced by the presence of more than $5 \%$ of studies outside the area bounded by the two $95 \%$ confidence interval lines in parallel to the centrally positioned line showing an unweighted regression of z-scores on the inverse of the standard error with the intercept constrained to zero.

Moreover, the Galbraith plot (Figure 2) depicts two of the seven selected studies lying outside the twoconfidence-interval region represented by two parallel lines enclosing a regression line, which suggests the presence of both heterogeneity and publication bias, albeit examining the latter is considered meaningless when between-study inconsistency is substantial.

However, heterogeneity was inevitable in this metaanalysis because, in most investigations exploring the influence of gamification elements on students' motivation, the average group score on the corresponding questionnaire is utilized to measure the intervention effectiveness. Accordingly, from such results, as mentioned earlier, it is impossible to ascertain how many participants had a positive result upon completion of the experiment, unlike biomedical research.

\section{DISCUSSION}

The scope of this meta-analysis was limited to the application of gamification to magnify higher education students' academic motivation. As for the initial research question, empirical evidence considered here favours an ability of educational gamification to encourage students' motivation for learning. There are limitations in this paper, including the small number of reviewed primary studies. However, the present analysis was underpowered by ex-ante inhomogeneous effect sizes, owing primarily to the use of a proportion meta-analysis not entirely appropriate for the extracted data. However, bearing in mind that most studies of interest utilize the survey method to examine levels of participants' motivation, we believe it is even more misleading to meta-analytically aggregate those responses, as was done in earlier research, given the discrepancies between the questionnaires used.

Overall, game design elements incorporated into the learning process were found to be significantly motivating for only about one-third of higher education students involved in the studies observed herein. At the same time, it is reasonable to assume that even in those experiments where gamification proved unable to increase learning motivation, the intervention was still effective for some part of the sample. Hence, the actual effectiveness is presumably around $50 \%$. It is safe to say that these findings mirror contradictory pictures 
emerging from several existing empirical investigations into the impacts of gamification on academic motivation.

When attempting to address the problem of mixed results, prior meta-analysts have resorted to evaluating the effectiveness of educational gamification depending on the type of game design element, context, and other moderating factors. For example, when [13] looked into moderator variables within their meta-analytic work, they identified that gamification blending competition and collaboration might serve as a source of motivation as opposed to settings restricted to competition. In turn, discussing outcomes from their experiment using a gamification plugin for an e-learning platform, [26] note some students admitted post facto that they were not encouraged by competing with groupmates for a rank in the leaderboard.

Furthermore, [13] state that only those gamification implementations lasting one to six months were motivating for participants, which cannot be supported by evidence from the present research where interventions lasting three months and a year reported a significant result.

It is worth noting that [27] and [14] complained earlier about the limited gamification design elements implemented in educational settings that amounted mainly to extrinsic rewards like points, leaderboards, and badges. Those may bring the risk of eroding intrinsic motivations with the shift to extrinsic motivation when learning activities are performed merely to attain an outcome rather than because of desire for the activities themselves [28]. The same research design drawback is true for the primary studies reviewed herein, which could be a speculative explanation for the observed marginal positive effects of gamification. Anyway, it has to be acknowledged that those sub-split moderator analyses have each time only led to rather blurry and unstable findings.

Arguably, the solution lies in dealing with far deeper dimensions. Particularly, [29] argued that it is important whether a game type is appropriate to the learning content and whether the latter is suitable for a game at all, referring to [30] as an illustration. In addition, [31] and [22] advocate that the effectiveness of applying gamification to enhance the level of motivation for studying depends largely on whether the game elements support certain psychological needs of students, which is consistent with the postulates of the self-determination theory. On top of that, [32] emphasizes the worth of game thinking for applying gamification in an educational context. That is, an experimenter or practitioner should feel how the operationalized gamification elements influence the educational process and keep on promoting it based on the feedback from the learners.

Altogether, the above perhaps negates the probability of discovering some universally successful gamification solution, even within a given contingent. Nonetheless, further research seems to be the only reasonable strategy for improving educational gamification. In this sense, we support the recommendation for future researchers [28] to try alternative game design elements like quests instead of those overused.

\section{CONCLUSION}

To summarize, the present study results do not support the suggestion that gamified learning activities may be effective in facilitating learning motivation among higher education students. Despite all the limitations, we hope the current paper could contribute to the field by aiding in debiasing decision-making regarding the gamification of learning activities.

\section{ACKNOWLEDGMENTS}

The authors are indebted to Sergey Sergeevich Kozhevnikov for English language editing.

\section{REFERENCES}

[1] Zainuddin Z. Students' learning performance and perceived motivation in gamified flipped-class instruction. Comput Educ 2018; 126: 75-88.

https://doi.org/10.1016/j.compedu.2018.07.003

[2] Buckley P, Doyle E. Gamification and student motivation. Interact Learn Environ 2016; 24(6): 1162-1175. https://doi.org/10.1080/10494820.2014.964263

[3] Tang CM, Chaw L. Driving high inclination to complete massive open online courses (MOOCs): motivation and engagement factors for learners. Electron J E-learn 2019; 17: 118-130. https://doi.org/10.34190/JEL.17.2.05

[4] Olsson M, Mozelius P, Collin J. Visualisation and gamification of e-learning and programming education. Electron J E-learn 2016; 13(6): 452-465.

[5] Fotaris $P$, Mastoras $T$, Leinfellner R, Rosunally $Y$. Climbing up the leaderboard: An empirical study of applying gamification techniques to a computer programming class. Electron J E-learn 2016; 14(2): 94-110.

[6] Ryan RM, Deci EL. Intrinsic and extrinsic motivations: Classic definitions and new directions. Contemp Educ Psychol 2000; 25(1): 54-67.

https://doi.org/10.1006/ceps.1999.1020

[7] Botnaru D, Orvis J, Langdon J, Niemiec CP, Landge SM. Predicting final grades in STEM courses: A path analysis of 
academic motivation and course-related behavior using selfdetermination theory. Learn Motiv 2021; 74: 101723. https://doi.org/10.1016/j.Imot.2021.101723

[8] Su CH, Cheng $\mathrm{CH}$. A mobile gamification learning system for improving the learning motivation and achievements. J Comput Assist Learn 2015; 31(3): 268-286.

https://doi.org/10.1111/jcal.12088

[9] Fu QK, Lin CJ, Hwang GJ, Zhang L. Impacts of a mind mapping-based contextual gaming approach on EFL students' writing performance, learning perceptions and generative uses in an English course. Comput Educ 2019; 137: 59-77.

https://doi.org/10.1016/j.compedu.2019.04.005

[10] Göksün DO, Gürsoy G. Comparing success and engagement in gamified learning experiences via Kahoot and Quizizz. Comput Educ 2019; 135, 15-29.

https://doi.org/10.1016/j.compedu.2019.02.015

[11] Pelikan ER, Lüftenegger M, Holzer J, Korlat S, Spiel C, Schober B. Learning during COVID-19: The role of selfregulated learning, motivation, and procrastination for perceived competence. Z Erziehwiss 2021; 24(2): 393-418 https://doi.org/10.1007/s11618-021-01002-x

[12] Gottfried AE, Nylund-Gibson K, Gottfried AW, Morovati D, Gonzalez AM. Trajectories from academic intrinsic motivation to need for cognition and educational attainment. J Educ Res 2017; 110(6): 642-652. https://doi.org/10.1080/00220671.2016.1171199

[13] Sailer M, Homner L. The gamification of learning: A metaanalysis. Educ Psychol Rev 2020; 32(1), 77-112. https://doi.org/10.1007/s10648-019-09498-w

[14] Huang R, Ritzhaupt AD, Sommer $M$, et al. The impact of gamification in educational settings on student learning outcomes: A meta-analysis. Educ Technol Res Dev 2020; 68(4): 1875-1901 https://doi.org/10.1007/s11423-020-09807-z

[15] Manzano-León A, Camacho-Lazarraga P, Guerrero MA, et al. Between level up and game over: A systematic literature review of gamification in education. Sustain 2021; 13(4): 2247.

https://doi.org/10.3390/su13042247

[16] Richardson M, Abraham C, Bond R. Psychological correlates of university students' academic performance: A systematic review and meta-analysis. Psychol Bull 2012; 138(2): 353387.

https://doi.org/10.1037/a0026838

[17] Cerasoli CP, Nicklin JM, Ford MT. Intrinsic motivation and extrinsic incentives jointly predict performance: A 40-year meta-analysis. Psychol Bull 2014; 140(4): 980-1008. https://doi.org/10.1037/a0035661

[18] Ferriz-Valero A, Østerlie O, García Martínez S, García-Jaén M. Gamification in physical education: Evaluation of impact on motivation and academic performance within higher education. Int J Environ Res Public Health 2020; 17(12): 116.

https://doi.org/10.3390/ijerph17124465
[19] Lin L, Xu C. Arcsine-based transformations for meta-analysis of proportions: Pros, cons, and alternatives. Health Sci Rep 2020; 3(3): 1-6. https://doi.org/10.1002/hsr2.178

[20] Frost RD, Matta V, Maclvor E. Assessing the efficacy of incorporating game dynamics in a learning management system. J Inf Syst Educ 2015; 26(1), 59-70.

[21] Stansbury JA, Earnest DR. Meaningful gamification in an industrial/organizational psychology course. Teach Psychol 2017; 44(1): 38-45 https://doi.org/10.1177/0098628316677645

[22] Van Roy R, Zaman B. Need-supporting gamification in education: An assessment of motivational effects over time. Comput Educ 2018; 127: 283-297. https://doi.org/10.1016/j.compedu.2018.08.018

[23] Garcia-Cabot A, Garcia-Lopez E, Caro-Alvaro S, Gutierrez-Martinez JM, de-Marcos L. Measuring the effects on learning performance and engagement with a gamified social platform in an MSc program. Comput Appl Eng Educ 2020; 28(1), 207-223. https://doi.org/10.1002/cae.22186

[24] Kyewski E, Krämer NC. To gamify or not to gamify? An experimental field study of the influence of badges on motivation, activity, and performance in an online learning course. Comput Educ 2018; 118: 25-37. https://doi.org/10.1016/j.compedu.2017.11.006

[25] Suurmond R, van Rhee H, Hak T. Introduction, comparison, and validation of Meta-Essentials: A free and simple tool for meta-analysis. Res Synth Methods 2017; 8(4): 537-553. https://doi.org/10.1002/jrsm.1260

[26] Domínguez A, Saenz-de-Navarrete J, De-Marcos L, Fernández-Sanz L, Pagés C, Martínez-Herráiz JJ. Gamifying learning experiences: Practical implications and outcomes. Comput Educ 2013; 63: 380-392. http://dx.doi.org/10.1016/j.compedu.2012.12.020

[27] Dicheva D, Dichev C, Agre G, Angelova G. Gamification in education: A systematic mapping study. J Educ Technol Soc 2015; 18(3): 75-88.

[28] Hanus MD, Fox J. Assessing the effects of gamification in the classroom: A longitudinal study on intrinsic motivation, social comparison, satisfaction, effort, and academic performance. Comput Educ 2015; 80: 152-161. http://dx.doi.org/10.1016/j.compedu.2014.08.019

[29] Kim B. Designing gamification in the right way. Libr Technol Rep 2015; 51(2): 29-35.

[30] Adams DM, Mayer RE, MacNamara A, Koenig A, Wainess R. Narrative games for learning: Testing the discovery and narrative hypotheses. J Educ Psychol 2012; 104(1): 235-249. https://doi.org/10.1037/a0025595

[31] Trenshaw KF, Revelo RA, Earl KA, Herman GL. Using selfdetermination theory principles to promote engineering students' intrinsic motivation to learn. Int J Eng Educ 2016; 32(3): 1194-1207.

[32] Alsawaier RS. The effect of gamification on motivation and engagement. Int J Inf Learn Technol 2018; 35(1): 56-79. https://doi.org/10.1108/IJILT-02-2017-0009

\section{https://doi.org/10.6000/2292-2598.2021.09.04.9}

(c) 2021 Mamekova et al.; Licensee Lifescience Global.

This is an open access article licensed under the terms of the Creative Commons Attribution Non-Commercial License (http://creativecommons.org/licenses/by-nc/3.0/) which permits unrestricted, non-commercial use, distribution and reproduction in any medium, provided the work is properly cited. 